\title{
BEYOND SEGMENTED INSTRUCTIONAL ANIMATION AND ITS ROLE IN ENRICHMENT OF EDUCATION AND TECHNOLOGY
}

\author{
Dr. Nidal Zaki Amarin \\ Faculty of Arts \\ Al-Zaytoonah University of Jordan, Jordan
}

\begin{abstract}
Animation usually offers the advantage of delivering better representations of dynamic concepts. Compared with the static images and text; animation can present procedural information (e.g. social activities and/or biochemical reaction) more explicitly as they show the steps in an orderly manner. Quite a few empirical studies show promising results of animation reflected on learning (e.g. Trevisan, Oki and Senger, 2009; Hays, 1996). There are, however, there are some limitations to such results. Designing and developing quality animation for teaching and learning can sometimes be challenging (Morrison, Tversky and Betrancourt, 2000). Kesner and Linzey (2005) found no improvement on students' learning in using animation in their study. Thus, researchers may encounter case factors that govern successful use of animation in teaching and learning processes.
\end{abstract}

\section{KEYWORDS}

Instructional animation, 3D Visualization, Segmenting principle, Multimedia learning.

\section{INTRODUCTION}

Animation, moving illustrated materials, are being used increasingly frequently in schools to depict dynamic changes over time and space, and illustrate phenomena or concepts that might be otherwise difficult to visualize (Nakhleh, 1992; Mayer \& Moreno, 2002; Cook, \& Levinson, 2009; Kozma\&Russel, 2005). Studies from many countries have demonstrated positive effects in the use of different and innovative methodologies and visualization technologies on students' understanding of central scientific concepts (Wu \& Shah, 2004; Kozma\&Russel, 2005; Nakhleh, 1992). Nevertheless, the effectiveness of the animation depend on the student's personality, it involves memory, the cognitive load (Mayer \& Moreno, 2002), the structure of the animation used and the methodology of using the animation in the classroom (Ruiz et al., 2009; Wu \& Shah, 2004; Mayer, 2005). Research addressing whether animation help learners understand dynamic phenomena has produced positive as well as negative results (Ainsworth 2008; Schnotz and Rasch 2005). One reason for this variety of results is that animation is a general term that refers to different forms of representation. While investigating the use of animation, some researchers indicated positive effect on students' learning process (Najjar 1998;Rieber 1990; Williamson and Abraham1995) and thinking skills (Schnotz and Kürschner 2008). Other researchers claim that animation may carry potential for misconceptions since in most cases they are simplified version of a phenomenon (Schnotz and Rasch 2005). 
In other words, instructional animation are dynamic visualizations that display a series of pictures for educational purposes. They are often used to illustrate dynamic changes within complex processes by depicting the motion or trajectory of processes (Betrancourt\&Tversky, 2000; Hoffler\&Leuthner, 2007), such as the information of lightning (Schmidt-Weigand\&Scheiter, 2011), or the motions of electrons (Yang, Andre, \&Greenbowe, 2003). Animation have been shown to be more effective that static graphicsin helping learners build mental models of processes involving change over time (Hoffler\&leutner, 2007; Wouters, Paas, \& van Merriënboer, 2008).

However, animation are not always superior or static graphics, because they may impose additional cognitive load Hegarty, Kriz, \& Cate, 2003; Mayer, Hegarty, \&Cambell, 2005; Phan, 2011; Spanjers, Wouters, van Gog, \&Merriënboer, 2010; Tversky, Morrison \&Betrancourt, 2002). For example, the information portrayed in complex or fast-paced animation is frequently too transient to enable essential cognitive processing (Mayer \& Moreno, 2003). In other words, the transiencyof information may not provide learners with sufficient time to process all of the elements in an animation (Hegarty et al., 2003). This may hinder learning by inducing high cognitive load (Ayres \&Paas, 2007; Spanjers, van Gog, \& van Merriënboer, 2010).

However, animation can be designed to reduce cognitive overload (Ayres \&Paas, 2007) by visually cueing important information (e.g., de Koning, Tabbers, Riders, \&Paas, 2007), presenting related information before animation (e.g., Mayer, Mathias, \&Wetzell, 2002). With the rapid progress in the computer and multimedia technologies, it has become feasible to integrate multimedia technologies into the teaching and learning process. What has been the conventional teacher-centered teaching approach is now seeing a shift into one which emphasizes on studentcentered learning approach. There is a body of evidence that supports the benefit of using technology, such as multimedia elements in the form of 2-Dimention (2-D) and 3-Dimention (3D) animation to assist in learning. "3-D modeling tools can be used to create representations of systems, which can then be manipulated to represent processes" (Clark, Wiebe\& Shown, 1996).

The inclusion of historical events and figures that helps to shape the world of animation has been important for generating learner interests and the development of a strong knowledge base. Providing background information only when needed helps the learner retain key technological advances and contributions to the filed (Williams, 2000). A firm understanding of the history of the subject creates an appreciation for the content and creates a foundation for the learner to use to expand his/her understanding and skills (Davis \&Krajcik, 2005)

\section{CONCEPT OF ANIMATION AND UNDERLYING THEORIES}

An animation is a series of images designed so that each image appears as an alteration of the previous one, and in which the sequence of images is determined by either the designer or the user (Betrancourt, 2005). Further, Mayer \& Moreno (2002) clarify animation as comprising a simulated motion picture displaying the movement of artificially created objects, by contrast with the video motion picture, which depicts the movement of real objects. Static graphics are depictions of artificial objects, whereas photographs are static pictures of real objects (Mayer \& Moreno, 2002).

Animation can illustrate dynamic changes over time and location, or facilitate the understanding of complex concepts, systems or structures by visualizing relationships among component parts. Animation can be classified along various dimensions including the nature of the process being visualized, the level of the learner interactivity, the dimensionality and the level of abstraction as shown in the following table. 
International Journal of Computer Graphics \& Animation (IJCGA) Vol.6, No.3, July 2016

Table 1: Domains by which animation may be classified, adapted from J G Ruiz et al. 2009

\begin{tabular}{|c|c|c|c|}
\hline Domain & Category & & Description \\
\hline \multirow[t]{3}{*}{ Process visualized } & Transformation & & $\begin{array}{l}\text { Process involves changes in form that involve alterations to the graphic } \\
\text { components in key characteristics such as size, shape, color or texture }\end{array}$ \\
\hline & Translation & & $\begin{array}{l}\text { Process involves changes in position involving motion of whole entities } \\
\text { from one location to another }\end{array}$ \\
\hline & Transition & & $\begin{array}{l}\text { Process involves changes such as the appearance or disappearance of } \\
\text { entities, fully or partly }\end{array}$ \\
\hline \multirow[t]{2}{*}{ Interactivity } & Non-interactive & & $\begin{array}{l}\text { Animation plays at a constant rate and for set length of time (no learner } \\
\text { control) }\end{array}$ \\
\hline & Interactive & & $\begin{array}{l}\text { Learner has some degree of control over the animation sequence, visible } \\
\text { layers, level of abstraction or play rate }\end{array}$ \\
\hline \multirow[t]{2}{*}{ Dimensionality } & Two-dimensional & & \\
\hline & Three-dimensional & & \\
\hline \multirow[t]{2}{*}{ Level of abstraction } & $\begin{array}{l}\text { Iconic/symbolic } \\
\text { representational }\end{array}$ & or & Animation displays a visible phenomenon, usually a realistic representation \\
\hline & Conceptual/abstract & & Animation illustrates non-visible concepts \\
\hline
\end{tabular}

Classifications are important because research into one type of animation may or may not apply to the other classes. Theories of learning are especially important in understanding the role and design of animation in teaching and learning. These theories propose that humans learn (construct knowledge) by perceiving and processing information in working memory and then organizing and storing this information in long-term memory. Stored information can be recalled into working memory as needed. Every learning theory has its own concepts and views on learning. Clark (1983) stated that there has been a paradigm shift in the development of education that is from the behaviorist theory to the cognitive and constructivist theories point of view. The following subsections describe these three primary principles in learning:

\section{Behavioral Theory}

Thorndike and Pavlov studied behaviorism in the turn of the twentieth century. The theory of behaviorism basically means that every response to a conditional stimulus is a conditioned response. The implication is that humans learn many behaviors because of their pairing with basic human needs and responses, such as the need for food, sleep, reproduction, and the like. The use of reward and punishment is also said to be part of modifying a behavior. This work was refined and popularized by B.F. Skinner (Alessi \& Trollip, 2001) and gave rise the behavioral school of psychology and learning. Some of the basic behavioral rules are as follows:

$\checkmark$ Behavior that is followed by positive environmental effects (known as positive reinforcement or reward) increases in frequency.

$\checkmark$ Behavior that is followed by the withdrawal of negative environmental effects (known as negative reinforcement) also increases in frequency.

$\checkmark$ Behavior that is followed by a negative environmental effect (punishment) decreases in frequency. 
$\checkmark$ When behavior that was previously increased in frequency though reinforcement is no longer reinforced, it decreases in frequency (known as extinction). Alessi \& Trollip (2001).

According to Hartley and Davies (1978), a few of thesebehaviorism principles were used widely in education which includes the following:

$\checkmark$ Learning process becomes easier when students follow the active process of learning.

$\checkmark$ Learning materials are arranged in logical order to ease students' learning and encourage feedback.

$\checkmark$ Each response must have immediate feedback for students to learn from their mistakes.

$\checkmark$ Each student response must be given a positive or negative reinforcement.

The implication of behavioral theory to this research paper is inevitable. Although behaviorist systems promote teacher-centered learning, this system promotes a student-centered learning environment, which integrates to the positive principles of behaviorism with a cognitiveconstructivist approach.

\section{Cognitive Theory}

Cognitive theory takes its name from the word cognition, which means the process of knowing. Cognitive psychology puts emphasis on unobservable constructs, such as the mind, memory, attitudes, motivation, thinking, reflection, and other presumed internal processes. The most important study in cognition is based on information-processing approach. In computer science, information processing theories attempt to describe how information in the world enters through our senses, becomes stored in memory, is retained or forgotten, and is used. Most information processing approaches includes the notion that memory and thinking have a limited capacity, which accounts for failures in attention and in memory. Another part of cognitive psychology is semantic network. This theory attempts to parallel how biologists view connections of human brain. In the semantic network such as the brain, learning may be represented by removing or adding links between nodes or by creating changing nodes. For example, new knowledge may also be so surprising that people interpret the new information in a way that is congruous with existing knowledge or beliefs. But this new knowledge may become so clear that eventually, existing knowledge must also change to remain acceptable in light of the new knowledge (Alessi \& Trollip, 2001; Simonson et al., 2003).

Prominent figures in cognitivism such as Bruner, Piaget and Papert gave emphasis on concepts as follows (Simonson et al., 2003):

$\checkmark$ How knowledge is arranged and structured.

$\checkmark$ Students' readiness to learn.

$\checkmark$ Give importance to intuition and intellectuality.

$\checkmark$ Motivation and positive outlook on learning.

According to the cognitive theory, humans need to see things in a concrete manner to understand better. As students browse along, they will see a proper sequence to the learning process. 


\section{Constructivist Theory}

Constructivism is where each individual learner combines new information with existing knowledge and experiences (Jonassen, 1999). Constructivism is also a philosophical view. The objectivist philosophy, or world view, hold that there is an objective world that is perceived more or less accurately through the senses, and that learning is the processes of correctly interpreting the senses and responding correctly to objects and events in the events in the real world.

Constructivism is a relatively a recent branch of cognitive psychology that has had a major impact on the thinking of many instructional designers. Constructivist thinking varies broadly on many issues, but the central point is that learning is always a unique product 'constructed' as each individual learner combines new information with existing knowledge and experiences. Individual have learned when they have constructed new information with existing knowledge and experiences. Individual have learned when they have constructed new interpretations of the social, cultural, physical, and intellectual environments in which they live (Dick \& Carey, 2005).

There are different schools of constructivism thought. For example, according to social constructivism, learning is inherently social. What we learn in a function of social norms and interpretations, and knowledge is not simply constructed by the individual, but by social groups. Moderate constructivism maintains that there is indeed a real world but our understanding of it is very individual and changing. More radical constructivism holds that we can never really know the exact nature of the real world, so it is only our interpretation of that matter.

One of the more substantial aspects of constructivist thinking is the basis of situated learning (Moore et al., 1994). The theory of situated learning assumes that learning always occurs in certain context and the context in turn significantly affects learning. The main implication of situated learning theory is that when properly designed, the situation in which learning takes place enhances transfer to other settings.

The anchored instruction approach is closely related to situated learning and is often attributed to one another. Anchored instruction assumes that a learning environment should be embedded in a context that is like a real world: with real world imagery, goals, problems, and activities (Alessi \& Trollip. 2001). There are various principles or suggestions that typically promote ways to accomplish that goal and they are as follows (Alessi \& Trollip, 2001):

$\checkmark$ Emphasize learning rather than teaching.

$\checkmark$ Emphasize the actions and thinking of learners rather than of teachers.

$\checkmark$ Emphasize active learning.

$\checkmark$ Use discovery or guided discovery approaches.

$\checkmark$ Encourage learner constructivism of information projects.

$\checkmark$ Have a foundation in situated cognition and its associated notion of anchored instruction.

$\checkmark$ Use cooperative learning activities.

$\checkmark$ Use purposeful, real or authentic learning activities.

$\checkmark$ Emphasize learner choice and negotiation of goals, strategies, and evaluation methods.

$\checkmark$ Encourage personal autonomy on the part of the learners.

$\checkmark$ Support learner reflection.

$\checkmark$ Support learner ownership of learning and activities.

$\checkmark$ Encourage learners to accept and reflect on the complexity of the real world.

$\checkmark$ Use authentic tasks and activities that are personally relevant to learners.

Constructivism basically combines new information with existing knowledge and experiences. They were told that each sitting in a cinema is mutually exclusive and no two persons will have to share a seat. The same concept is applied in memory management, where each data is given a 
specific address. The analogy used in the cinema sitting scenario is then repeated in a few slides for recall purposes. The usage of a truck is used to carry data into a large rack. This concept is used so that students can relate the usage of a truck in a store at a hypermarket to store supplies with the same idea related to contiguous memory allocation in the Central Processing Unit (CPU). All these concepts are part of constructivist approach to learning.

\section{COGNitive Theory OF MULTIMEdia Learning}

Tannenbaum (2000) defines multimedia as "an interactive computer-mediated presentation that includes at least two of the following elements: text, sound, still graphic images, motion graphics, and animation." The choice of media is also flexible; this may incorporate audio, video, animation, and text in varying quantities. One particularly relevant and established theory of instructional design is the cognitive theory of multimedia learning (Mayer, 1984, 1997, 2001). At first blush, the name of this theory is somewhat misleading in that it appears computer centric. However, multimedia learning theory is less about the type of media used in educational settings and more about memory and how learners process information. In fact, Mayer's work has been generalizes to the e-Learning environment, with the vast majority of principles remaining the same (Clark \& Mayer, 2008). Essentially, multimedia learning theory posits a dual modality because it emphasize what a learner sees and hears for creating meaningful learning (Mayer, 1997; Mayer \& Moreno, 1998). As such, Mayer suggests the theory may be more appropriately referred to as a multimodal (vs. multimedia) learning theory.

Mayer's theory holds that auditory and visual stimuli processed first in the sensory memory by the student, and then selected words and images are organized into the learner's working memory. Learners integrate the visual model of what they see with the auditory model of what they hear into their functioning memory; this integrated model becomes part of the students' long-term memory when it becomes part of their storehouse of knowledge (2001). Ultimately, the multimedia theory claims that coordinated presentation of narration and pictures is effective because it guides learners' cognitive processes in selecting and organizing relevant information to build cause-and-effect relationships (Mayer, 1997). The theory makes a dual channel assumption, meaning learning stimuli are processed in either the auditory or visual channel in the brain. Pictures, screen text, and animation are handled in the visual/pictorial channel, and sounds and narration are dealt with in the auditory channel. Important to the original theory are thus the learner's visuospatial processing and his or her phonological loop, which deals with processing language (Baddeley 1992, 1999). Second, the theory presumes limited capacityfor the auditory and visual channels. Put simply, each channel is capable of processing only so much material at one time. Working memory theory (Baddeley, 1992) and cognitive load theory (Chandler \&Sweller, 1991; Miller, 1956) also support a limited-capacity principle in learning. The most direct design principle that follows from cognitive load theory is that extraneous information should be omitted to preserve learners' attentional resources. The third assumption of multimedia learning theory is a focus on knowledge construction, versus knowledge acquisition, meaning it is assumed that the learner is trying to understand and make sense of the material rather than acting as a passive receptacle. However, it will be argued later that the findings based on this theory are also likely applicable in more passive instructional scenarios. 


\section{The Multimedia Learning Model}

Based on the multimedia learning model in Figure 1, the arrows represent the steps of processing involved in the cognitive theory of multimedia learning: (a) selecting relevant words, (b) selecting relevant images, (c) organizing selected words, (d) organizing selected images, and (e) integrating verbal and visual representation as well as prior knowledge.

Figure 1:Visual Representation of the Cognitive Theory of Multimedia Learning. R E Mayer, (2001)

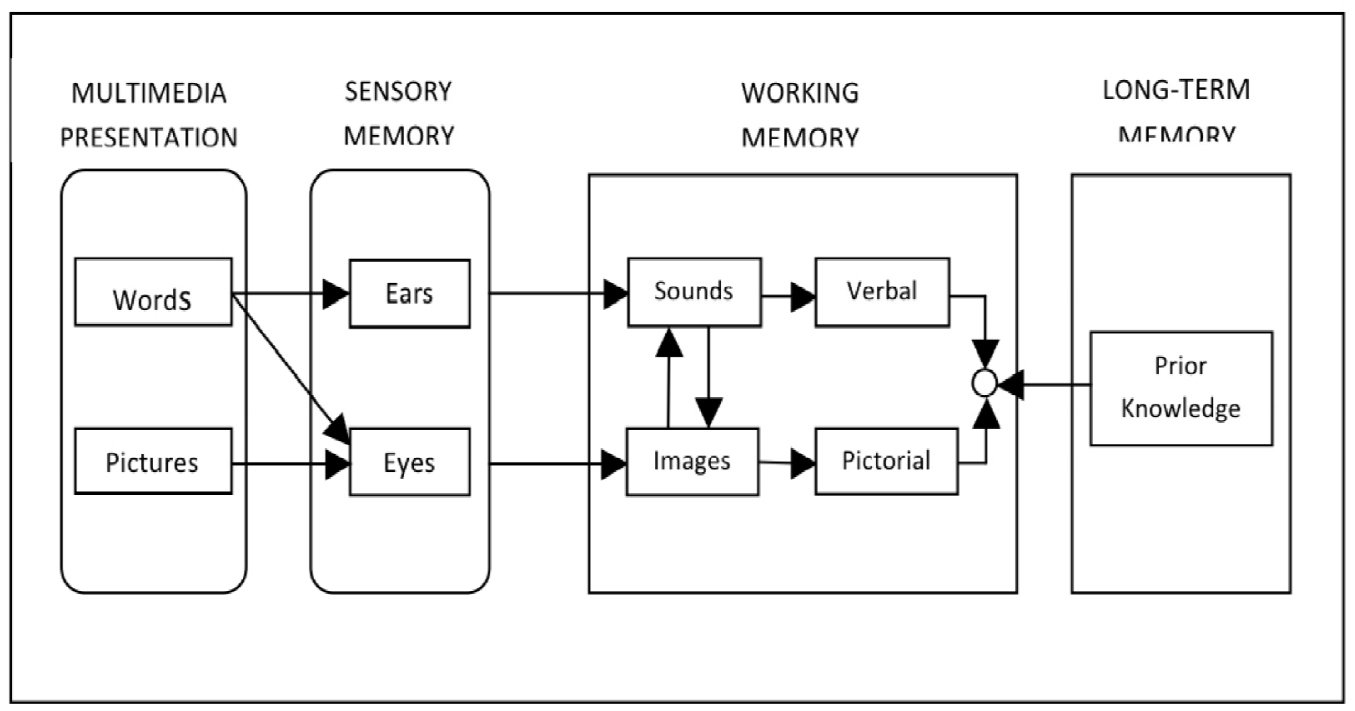

Mayer's (2001; 2009) experiments were focused on the auditory/verbal channel and the visual channel. He defines multimedia as the representation of material using both words and pictures. Thus, the definition of multimedia is narrowed down to two forms of information: verbal and pictorial or visual. This is because the research base in cognitive psychology is most relevant to this definition.

This model is based on three primary assumptions (Mayer, 2009) as follows:

$\checkmark$ Visual auditory experiences or information are processed through separate and distinct information processing 'channels'.

$\checkmark$ Each information processing channel is limited in its ability to process experience or information

$\checkmark$ Processing experiences or information in the channels form an active process designed to construct coherent mental representations.

Throughout the 1990s and beyond, Mayer and his colleagues have conducted research investigating the nature and effects of multimedia presentations on human learning. Mayer's (2001; 2009) theory on multimedia learning involves seven principles that can be applied for the design of multimedia messages as indicated in Figure 2. 
Figure 2: Seven Research-based Principles for the Design of Multimedia Messages (Adapted from Mayer, 2001)

1. Multimedia Principle: Students learn better from words and pictures than from words alone.

2. Spatial Contiguity Principle: Students learn better when corresponding words and pictures are presented near rather than far from each other on the page or screen.

3. Temporal Contiguity Principle: Students learn better when corresponding words and pictures are presented simultaneously rather than successively.

4. Coherence Principle: Students learn better when extraneous words, pictures, and sounds are excluded rather than included.

5. Modality Principle: Students learn better from animation and narration than from animation and on-screen text.

6. Redundancy Principle: Students learn better from animation and narration than from animation, narration and on-screen text.

7. Individual Differences Principle: Design effects are stronger for low-knowledge learners than for high-knowledge learners and for high-spatial learners rather than for low-spatial learners.

Thus, learning is maximized when information is received through both visual and verbal inputs, and when extraneous cognitive load is minimized (Mayer \& Moreno, 2002). By empirically testing and revising this theory, Mayer has proposed a number of evidence-based principles of multimedia instructional design (Mayer, 2002).

\section{Connecting Animation To The Standards}

All types of animation apply drawing, layout, measurement, timing, teamwork, and other various skills and techniques. These include incorporating goals, objectives, techniques, and skills from drama, art, graphic communications, computer applications, and technology education. Specifically, using animation projects, design briefs, and units in technology education courses can address Standard 17 of Standards for Technological Literacy: Content for the study of Technology (STL) (ITEA [ITEEA], 2000/2002/2007). "Students will develop an understanding of and be able to select and use information and communication technologies" (p.166).

\section{Segmented - Animation Pauses}

The segmented principle states that "people learn better when a multimedia message is presented in user-paced segments rather than as a continuous unit" (Mayer, 2009, p. 175). The segmentation strategy was first explored in the context of reading. Several studies found that segmented text, grouped in meaningful units, was more beneficial for learning (i.e., recall and comprehension) than continuous text (Florax\&Ploetzner, 2010; Gaddy van den Broek, \& Sung, 2001; Glynn, Britton, \& Tillman, 1985; Hartley, 1986; Weiss, 1983). Spatially segmented text appeared to provide learners with the opportunity to stop the flow of information (Lusk et al., 2009) and the process the information more deeply. In a similar manner, multimedia researchers have examined the effectiveness of presenting dynamic instructional animations in smaller pieces (i.e., segments) rather than in a continuous format (Clark \& Mayer, 2011; Mayer, 2009; Spanjers, van Gog. \& van Merriënboer, 2012; Spanjers et al., 2011). Several studies have demonistrated the positive effects of segmentation in instructional animation (e.g., Hasler, Kersten, \&Sweller, 2007; Mayer \& Chandler, 2001; Moreno, 2007; Spanjers et al., 2011; van Gog \&Paas, 2008). 
Segmented - animation, with features that allow learners to control the segment viewing rather than passively viewing the whole aninmation continuously, could be a designsolution that addresses this limitation (Moreno, 2007; Mayer \& Moreno, 2003; Mayer \& Chandler, 2001). In segmented-animation design, the whole animation is broken into meaningful segments, including pauses or time breaks after each segment, and learner-control features to move from one segment another. Thus, pauses or time breaks between segments and learner-control features will allow learners to rehears, in order to extract the necessary information from one segment before moving on to the next. In addition, during these pauses, learners can analyze the visual spatial structure of the content on the screen, which is something that can be difficult to do when a display continuously changes (Lowe, 2004).

Spanjers et al. (2012) conducted another segmentation study designed to increase learner engagement by having learners create their own segments within a series of written worked examples. However, the results showed that asking learners to create their own segments required more mental effort (and reduce learning efficiency) than presenting learners with predefined segment pauses. Learner created segmentation appears to require extensive cognitive resources that may overload the cognitive system. Even though their study did not use animation, the results can be explained by the guidelines for designing effective video-based model prosed by Wouters, Tabbers, and Pass (2007). Their guidelines suggest that pacing with predefined segments would be beneficial for learners with low prior knowledge, whereas creating segments would be suitable for learners with high prior knowledge.

\section{Active - Passive Pauses}

Other strategies, besides segmentation, have been studied in conjunction with animation in order to increase their effectiveness. For example, Paas, Van Gerven, and Wouters (2007) showed a sequence of key frames from an animation directly after the animation. In other study, Mayer et al. (2003, Experiment 3) gave learners a question before showing an animation about the working of an electronic motor and told them that they would have to answer the question after the animation. Both of these methods successfully enhanced students learning by actively engaging students with the information presented in the animation. Interestingly, however, few studies have attempted to engage students in active processing activities between segments of an animation (i.e., during the pause period). This is an important area of research since pauses between segments of an animation are only effective to the degree that learners actually use the time during pauses to process relevant information (Wouters et al., 2008), and some researchers have questioned whether use pause time effectively (Spanjers, van Gog, Wouters et al., 2012). Therefore, the primary purpose of this study was to explore the effectiveness of providing different types of student engagement during pauses in an animation.

The conventional pause between animation segments can be referred to a passive pause no instructional activity is presented during the pause. On the other hand, an active pause when an instructional activity is presented during the pause (e.g., answering a question) (Cheon et al., in press). Presenting learners with an engaging instructional activity during a pause in an animation is likely to make the pause period more meaningful, since the activity should enhance the cognitive processing of information from the previous segment. For example, Cheonet al. (in press) presented embedded questions that required learners to retrieve information from the previous animation segment. In their study, the active pause group outperformed a passive pause group on recall and transfer tests; the authors conducted that this kind of active pauses promote germane cognitive load by enhancing schema construction. However, the positive effects of the active pause in their experiment might have been caused by the extra time spent by learners who responded to embedded questions because the pauses in their study were learner-controlled. Little is known about the direct effects of embedded questions during an animation pause. Even less is 
known about how different types of instructional activities during pauses affect learning performance. In addition, the effects of active pausing on cognitive load (Paas, Tuovinen, \& Van Gerven, 2003) should be taken into consideration. The instructional activity presented during a pause may increase learners' mental effort as they strive to understand the information depicted in animation (Wouters et al., 2008). Alternatively, active pauses may decrease mental effort for a test because learners have already encoded and retrieved information by the pause activity.

The aim of the present study was to determine the relative advantage of active pauses over passive on learning performance and mental effort in an instructional animation incorporating system-controlled pauses. Participants receiving passive pauses were instructed to either wait (i.e., no instruction to reflect) or to reflect on the information presented in the previous segment; participants receiving active pauses were asked to either write down everything they could remember from the previous segment (i.e., free recall) or answer short-answer test items during the pause period. The research questions were (a) How does pause type (active vs. passive) affect the learning performance of university students studying a segmented animation? And (b) How does pause type (active vs. passive) affect the mental effort of college students studying a segmented animation? It was hypothesized that active pauses would enhance learning outcomes (i.e., recall and transfer) more than passive pauses. Regarding mental effort, active pause groups were hypothesized to invest higher mental effort than the passive pause group during the instructional animation, but lower mental effort during the test phases.

\section{METHODOLOGY}

\section{Participant and design}

Ninety-nine undergraduate students from Al-Zaytoonah university participated in this study (Female: 50, Male: 49) the participants were enrolled in an undergraduate course on computer literacy, and the course had an instructional research module to provide students with an opportunity to participate in a study related to instructional technology. Participants were randomly assigned to one of the four experimental conditions (i.e., two passive pauses groups and two active pause groups): (a) passive pause, no-reflection, $n=29$, (b) passive pause, reflection, $\mathrm{n}=25$, (c) active pause, free recall, $\mathrm{n}=24$, and (d) active passive, short-answer, $\mathrm{n}=21$.

\section{Materials}

\section{Instructional animation}

The instructional animation consisted of a 160-second instructional animation about the formation of lightning (see Figure 3) created with Adobe Flash software. The animation was based on animation used by Mayer and Moreno (1998) and consisted of 16 frames, each depicting a step in the process of lightening formation. The animation was divided into four 40 -second segments (four steps per segment). The animation was accompanied by narration identical to the text used by Mayer and Moreno (1998). The narration explained each of the steps in the formation of lightning.

Differences between the conditions involved the type of activity required of students during the four pauses in the animation. The animation, including pauses, was system-controlled, and total time to complete the animation was 320 seconds (i.e., 40 seconds per segment and 10 seconds per pause). During pauses, the passive pause, no reflection group was presented with blank screen with the follow message typed in the middle of the screen: "Please wait. You will be moving to the next animation in 40 seconds." The passive pause reflection group was presented with the following message encouraging self-reflection on the mental they had just studies: "Please try to 
remember what you saw in the previous animation. You have40 seconds." The active pause, freerecall group with to the following message: "Please type as much of the information from the previous section that you can remember. You have 40 seconds." The active pause, short-answer group was presented with the following message followed by two short-answer questions pertaining segment, "Please answer the following questions. You have 40 seconds."

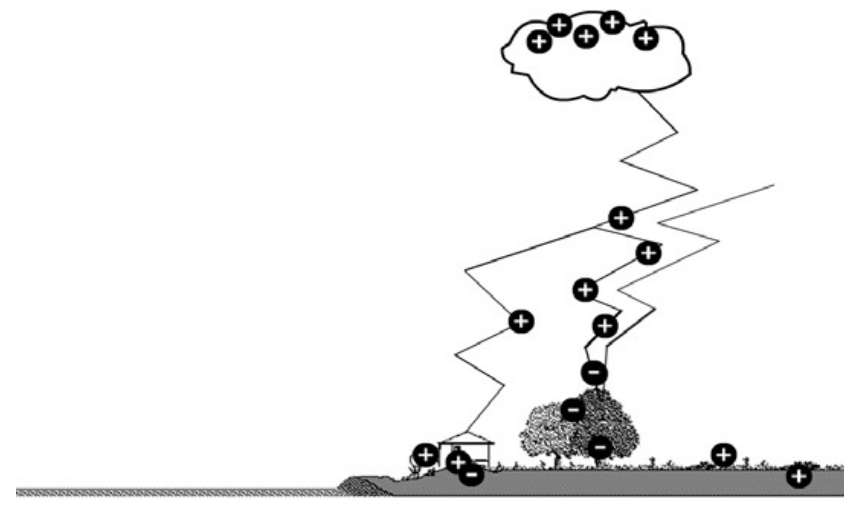

Figure 3.A screenshot of instructional animation

\section{Prior knowledge test}

Prior meteorology knowledge was collected from the participants using items developed by Mayer and Moreno (1998) and consisted of a seven-item meteorology-knowledge checklist (e.g., "I know what a cold front is __," "I know what a low pressure system is _ ”) and a self-rating that asked participants to rate their knowledge of meteorology on a 5-point scale (1=very little; $5=$ very much).

\section{Learning performance tests}

Learning performance was measured with two tests (i.e., recall test and transfer test). The recall test instructed the participants to type everything they could remember from the instructional animation they had just studied. Following Mayer and Moreno (1998), free recall performance was scored by awarding participants one point for each of the 19 idea units contained in the instructional text, resulting in a total of 19 points possible. The transfer test, also developed by Mayer and Moreno (1998), consisted of four open-ended questions that required participants to transfer their knowledge of the instructional animation to correctly answer the questions (e.g., "What could you do to decrease the intensity of lightning?"). the transfer test was scored by awarding from zero to 3 points per item, resulting in a total of 121 points possible.

\section{Mental effort rating}

A mental effort rating scale was used to measure mental effort invested in both the instruction and the test phases. The nine-point rating scale was developed by Paas (1992) and consisted of the following statement: "Please indicate how much mental effort you invested in this test ranging from 1 (Extremely low) to 9 (Extremely high)." This subjective self-rating measure is nonintrusive and has proven to be a reliable indication of the mental effort experienced by participants (Paas et al., 2003). 


\section{PROCEDURE}

The study was conducted in a computer lab with 15 to 20 participants in each experimental session. A research proctor began the study by instruction the participants to turn on their computer monitors and silently read the instructions pertaining to their randomly assigned condition. The participants were also informed that they would be given a series of brief assessment after their study of the material; however, they were not informed about the nature of the statements. They were next asked to complete the participant questionnaire including demographic information and prior knowledge. The participants then studied their assigned instructional animation. Since the animation including pauses was system-controlled, all groups completed the animation at the same time. After studying the instructional animation, the participants completed the recall test and then the transfer test.

\section{RESULTS}

Regarding prior knowledge of the learning material, there were no significant differences among groups in either of the prior knowledge measurements (Seven-item meteorology-knowledge checklist, $F(3,98)=1.616, p=.191$; self-rating question $F(3,98)=1.257, p=.294)$.

The research questions in this study were investigated trough one-way ANOVAs. The analyses showed that test scores were influenced by the types of pauses (research question\#1). However, mental effort scores were not significantly different (research question \#2). The means of each measure by group are presented in Table 2 .

Regarding recall test scores, the results revealed significant differences among the groups, $F(3$, $98)=4.861 ., \eta^{2}=.365, p=.003$. Post-hoc comparisons indicated that the mean scores for the active pause, free-recall group $(M=10.54, S D=3.13)$ was significantly higher than both passive conditions: no reflection $(M=7.31, S D=3.24)$ and reflection $(M=8.08, S D=3.51)$. However, the active pause, short-answer group $(M=8.86, S D=2.65)$ was not significantly different from any of the other groups.

Table 2: Means and standard deviation for recall, transfer, and mental effort by treatment group

\begin{tabular}{|llllll|}
\hline $\begin{array}{l}\text { Dependent } \\
\text { Variables }\end{array}$ & $\begin{array}{l}\text { Passive pause, } \\
\text { no-reflection } \\
n=29\end{array}$ & $\begin{array}{l}\text { Passive pause, } \\
\text { reflection } \\
n=25\end{array}$ & $\begin{array}{l}\text { Active pause, } \\
\text { free-recall } \\
n=24\end{array}$ & $\begin{array}{l}\text { Active pause, } \\
\text { short-answer } \\
n=21\end{array}$ & $p$ \\
\hline $\begin{array}{l}\text { Recall test scores } \\
\begin{array}{l}M=7.31 \\
(\mathrm{SD}=3.24)\end{array}\end{array}$ & $\begin{array}{l}M=8.08 \\
(S D=3.51)\end{array}$ & $\begin{array}{l}M=10.54 \\
(S D=3.13)\end{array}$ & $\begin{array}{l}M=8.86 \\
(S D=2.65)\end{array}$ & $.003^{*}$ \\
$\begin{array}{l}M=3.93 \\
\text { scores }\end{array}$ & $\begin{array}{l}M=4.52 \\
(S D=2.14)\end{array}$ & $\begin{array}{l}M=5.58 \\
(S D=1.31)\end{array}$ & $\begin{array}{l}M=4.90 \\
(S D=1.61)\end{array}$ & $.019^{*}$ \\
$\begin{array}{l}\text { Mental effort for } \\
\text { instruction }\end{array}$ & $\begin{array}{l}M=5.79 \\
(\mathrm{SD}=1.42)\end{array}$ & $\begin{array}{l}M=5.64 \\
(S D=1.63)\end{array}$ & $\begin{array}{l}M=6.21 \\
(S D=1.50)\end{array}$ & $\begin{array}{l}M=6.00 \\
(S D=1.70)\end{array}$ & .604 \\
$\begin{array}{l}\text { Mental effort for } \\
\text { recall test }\end{array}$ & $\begin{array}{l}M=6.59 \\
(S D=1.30)\end{array}$ & $\begin{array}{l}M=6.00 \\
(S D=1.47)\end{array}$ & $\begin{array}{l}M=6.50 \\
(S D=1.14)\end{array}$ & $\begin{array}{l}M=6.67 \\
(\mathrm{SD}=1.32)\end{array}$ & .285 \\
$\begin{array}{l}\text { Mental effort for } \\
\text { transfer test }\end{array}$ & $\begin{array}{l}M=6.38 \\
(S D=1.18)\end{array}$ & $\begin{array}{l}M=5.68 \\
(S D=1.28)\end{array}$ & $\begin{array}{l}M=6.08 \\
(S D=1.44)\end{array}$ & $\begin{array}{l}M=6.52 \\
(S D=1.47)\end{array}$ \\
\hline
\end{tabular}


There was also a significant transfer effect, $F(3,98)=3.459, \eta^{2}=.314, p=.019$. Post-hoc comparisons indicated that the transfer test scores in the active pause, free-recall group $(M=5.58$, $S D=1.31)$ were significantly higher than the scores in the passive pause, no reflection group $(M$ $=3.93, S D=2.25$ ). There were no significant differences among the other groups.

There was no effect for mental effort for instruction, $F(3,98)=.620, p=.604$, recall test, $F(3,98)$ $=1.281, p=.285$, and transfer test, $F(3,98)=1.884, p=.138$. Taken together, these results suggest that the active pause, free-recall condition positively affected learning over the passive pause groups without increasing the mental effort of the participants.

\section{DISCUSSION AND CONCLUSION}

In conclusion, the researcher wants to emphasize that animation improves learner's intellectual, emotional and social experience, as well as it may support the use of diverse teaching strategies and learning methodologies, and can promote diverse thinking skills among learners. Several researchers (Barak \&Dori 2005; Kaberman\&Dori 2009; Garcia et al. 2007; Williamson \& Abraham 1995) found that the integration of a multimedia and/or animation environment encourages learners' conceptual understanding and reasoning ability. In the use of 3-Dimensional animation, Korakakis et al. (2009) studied the specific types of visualization (3D illustrated, 3D animation and interactive 3D animation) contributed to learning. The results indicated that multimedia applications with interactive 3D animation as well as with 3D animation do in fact increase the interests of students and make the material more appealing to them. In summary, it can be stated that animation has mostly enhanced learning rather than detrimental to learning. In this case, the use of animation would lead to mixed results in terms of learners' understanding and performance, but it has mostly enhanced and improved learning process.

The positive effects of the active pause, free-recall condition (i.e., free recall test: $p=.003$, transfer test: $p=.019$ ) can be explained as resulting from an emphasis on germane cognitive load as opposed to extraneous cognitive load. Based on the limitations of working memory when processing large amounts of information (Baddeley, 2007), the segmenting principle asserts that presenting a continuous animation in small chunks can reduce learners' cognitive load (Mayer \& Moreno, 2003; Moreno \& Mayer, 2007). Thus, learners can process previously presented information during pauses between segments. The positive effect of pauses has been found in the previous studies, but the effect is clearly dependent upon the metacognitive skill and/or motivation of the learners, as they may not use the pause time effectively (Spanjers, van Gog, Wouters et al., 2012). The conventional pause was called as a passive pause in this study because there is no required task for learners. On the other hand, an active pause was proposed using embedded assessments between segments. We hypothesized that while the passive pause condition may reduce extraneous cognitive load, the active pause conditions should promote generative cognitive load by facilitating schema construction. The findings are consistent with the results obtained by Cheon et al. (in press) and more clearly illustrate the effects of an active pause condition. The previous study found that a short-answer question group outperformed a noreflection pause group, but these results might have been caused by the additional time spent by the active pause group. Therefore, the present study controlled the pause time to investigate whether learning performance differences were caused solely by the additional time afforded by the embedded questions. The results of the current study show that the active pause likely facilitates germane cognitive load by requiring learners to actively process material from the prior segment. Interestingly, it was the group asked to free recall rather than respond to short-answer questions that was responsible for the learning differences. We conjecture that because the shortanswer questions covered only two steps, out of four steps, in each segment they may have focused on only half of the material in each segment. Also, learners may not have had enough time to fully take advantage of the stimulus, because they had to read and understand two questions first in order to type their responses. Thus, with a system-controlled pace, we contend that free recall during pauses is superior to short answer. 


\section{REFERENCES}

[1] Ainsworth, S. (2008). How do animations influence learning? In: Robinson, D. Schraw, G. (eds). Current perspectives on cognition, learning, and instruction: recent innovations in educational technology that facilitate student learning. Information Age Publishing, New York, pp 37-67.

[2] Alavi, M., Leidner, D.E. (2001).Research commentary. Technology-mediated learning: A call for greater depth and breadth of research. Information System Research, 12(1), 1-10.

[3] Alessi, S. \& Trollip, S.R. (2001).Multimedia for learning: Methods and development. 3rd edition.MA: Allyn and Bacon.

[4] Ayres, P., \& Pass, F. (2007). Making instructional animation more effective: A cognitive load approach .Applied Cognitive Psycology, 2(6), 695-700.

[5] Baddeley, A. D. (2007). Working memory, thought and action. Oxford, UK:Oxford University Press.

[6] Baddeley, A. D. (1992). Working memory.Science, 255, 556-559.

[7] Baddeley, A. D. (1999) Human memory. Boston: Allyn \& Bacon.

[8] Baddeley, A. D. (2007). Working memory, thought and action.Oxford University Press.

[9] Barak, M. \&Dori, Y.J. (2005).Enhancing undergraduate students' chemistry understanding through project-based learning in an IT environment.Science Education, 89(1) 117-139.

[10] Betrancourt, M. (2005).The animation and interactivity principles in multimedia learning.In : Mayer, R., ed. The Cambridge Handbook of Multimedia Learning.New York, NY: Cambridge University Press, pp 287-296.

[11] Betrancourt, M., \&Tversky, B. (2000). Effect of computer animation on users' performance: A review. Le Travail Humain: A Bilingual and Multi-Disciplinary Journal in Human Factors, 63(4), 311-329.

[12] Chandler, P., \&Sweller, J. (1991). Cognitive load theory and the format of instruction.Cognition and Instruction, 8, 293-332.

[13] Chandler, P., \&Sweller, J. (1992). The split attention effect as a factor in the design of instruction.British Journal of Educational Psychology, 62, 233-246.

[14] Chapman, P., Selvarajah, S., \& Webster, J. (1999).Engagement in multimedia training systems. Proceeding og 32nd. Hawaii International Conference System Sciences. Maui, HI, IEEE Computer Society Press, 1032-1057.

[15] Clark, A.C., Wiebe, E.N., \& Shown, T. (1996). Future directions for graphics: A look at the new technical graphics curriculum in NC high schools. Paper presented at the Engineering Design Graphics Division Mid-Year Meeting, Raleigh, NC.

[16] Clark, R. (1983). Reconsidering research on learning from media.Review of Educational Research, 53(4), 445-459.

[17] Clark, R. C., \& Mayer, R.E. (2008).E-learning and the science of instruction (2nd,ed).San Francisco, CA: Jossey-Bass.

[18] Cook, D.A., Levinson, A.J., Garside, S., Dupras, D.M., Erwin, P.J. \&Montori, V.M. (2008). Internetbased learning in the health professions: a meta-analysis. JAMA, 300, 1181-96.

[19] Davis, E. \&Krajcik, J. (2005).Designing educative curriculum materials to promote teacher learning.Rducational Researcher, 34(1), 3-14.

[20] deKoning, B.B., Tabbers, H.K., Riders, R. M.J. P., \&Paas, F. (2007). Attention cueing as a means to enhance learning from an animation. Applied Cognitive Psychology, 21(6), 731-746.

[21] Dick, W. \& Carey, L. (2005).The Systematic Design of Instruction. Edited by S. Edition. Allyn \& Bacon, Boston: Pearson.

[22] Gaddy, M.L., van den Broek, P., \& Sung, Y.C. (2001).The influence of text cues on the allocation of attention during reading. In T. Sanders, J. Schilperoord\&Spooren (Eds.), Text representation: Linguistic and psycholinguistic aspects (pp. 89-110). Amsterdam, the Netherlands: Benjamins.

[23] Garcia, R.R., Quiros, O.J., Gallego, S.R., Martin, G.S. \&Fernanz, S.M. (2007).Interactive multimedia animation with macromedia flash in descriptive geometry teaching.Omputer Education, 49(3), 615639.

[24] Glynn, S. M., Britton, B. K., \& Tillman, M. H. (1985). Typographical cues in text: Management of the reader's attention. In D. H. Jonassen (Ed.), The technology of text (Vol. 2, pp. 192-210). Englewood Cliffs, NJ: Educational Technology Publications.

[25] Hartley, J. (1986). Planning the typographical structure of instructional text.Educational Psychologist, 21(4), 315-332. 
[26] Hartley, James \& Ivor, K. Davies. (1978). Note-taking: A critical review. Innovations in Education and Teaching International, 15(3), 207-224.

[27] Hays, T.A. (1996).Spatial Abilities and the Effects of Computer Animation on Short-term and Longterm Comprehension. Journal of Educational Computing Research.14(2), 139-155.

[28] Hegarty, M., Kriz, S., \& Cate, C. (2003).The roles of mental animation and external animation in understanding mechanical systems. Cognition and Instruction, 21(40, 325-360.

[29] Hoffler, T.N., \&Leutner, D. (2007). Instructional animation versus static pictures: A meta-analysis. Learning and Instruction. 17(6), 722-738.

[30] International Technology Education Association (ITEA/ ITEEA).(2000/2002/2007).Standards for technological literacy: Content for the study of technology. Reston, VA: Author.

[31] Jonassen, D. (1999). Designing constructivist learning environments. In Reigeluth, C. Instructional Design Theories and Models, pp. 217-239. Mahwah, NJ: Lawrence Erlbaum Associates.

[32] Jones, S., \&Scaife, M. (2000). Animated diagrams: An investigation into the cognitive effects of using animation to illustrate dynamic processes. In M. Anderson \& P. Cheng (Eds.), Theory and applications of diagrams. Lecture notes in artificial intelligence, no. 1889. Berlin: Springer, 231-244.

[33] Kaberman, Z., \&Dori, Y.J. (2009). Question posing, inquiry, and modeling skills of high school chemistry students in the case-based computerized laboratory environment. International Journal of Math Education, 7: 597-625.

[34] Kesner, M.H. \&Linzey, A.V. (2005). Can Computer-based Visual-spatial Lead to Increased Student Performance in Anatomy \& Physiology? The American Biology Teacher. 67(4), 206-212.

[35] Korakakis, G., Pavlatou, E. A., Palyvos, J.A., \&Spyrellis, N. (2009). 3D Visualization types in multimedia applications for science learning: A case study for 8th grade students in Greece. Computers \& Education, 52, 390-401.

[36] Kaiser, M. K., Proffitt, D. R., Whelan, S.M., \& Hecht, H. (1992). Influence of animation on dynamical judgments. Journal of Experimental Psychology : Human Perception and Performance, 18(3), 669-690.

[37] Kozma, R., Russel, J. (2005). Multimedia Learning of Chemistry Cambridge handbook of multimedia learning.(pp. 409-428). New York: Cambridge University Press.

[38] Large, A., Beheshti, J., Breuleux, A., \& Renaud, A. (1994). Multimedia and comprehension: A cognitive study. Journal of the American Society for information Science, 45(7), 515-528.

[39] Leidner, D. E., \&Jarvenpaa, S. (1995). The use of information technology to enhance management school education: A theoretical view. MIS Quarterly, 19(3), 265-291.

[40] Lowe, R.K. (2003). Animation and learning: Selective processing of information in dynamic graphics. Learning and Instruction, 13(2), 157-176.

[41] Lowe, R.K. (2004). Animation and Learning: Value for money?, in Atkinson, R., McBeath, C., JonasDwyer, D. \& Phillips, R. (ed.), Beyond the Comfort Zone: Proceedings of the 21st ASCILITE Conference (pp558-561), Perth, Australia, December.

[42] Mayer, R. E. (1984). Aids to text comprehension.Educational Psychologist, 19(1), 30-42.

[43] Mayer, R. E. (1997). Multimedia learning: Are we asking the right questions? Educational Psychologist, 32(1), 1-19.

[44] Mayer, R. E. (2001). Multimedia learning.Cambridge, UK: Cambridge University Press.

[45] Mayer, R. E. (2002). Multimedia learning.The Psychology of Learning and Motivation, 41(3), 85139.

[46] Mayer, R. E. (2005). Cognitive theory of multimedia learning. The Cambridge handbook of multimedia learning.(pp. 31-48). New York: Cambridge University Press.

[47] Mayer, R. E. (2009). Multimedia learning (2nded.). New York: Cambridge University Press.

[48] Mayer, R. E. (2001). When learning is just a click away: Does simple user interaction foster deeper understanding of multimedia messages? Journal of Educational Psychology,93(2), 390-397.

[49] Mayer, R. E., Hegarty, M., Mayer, S., \& Campbell, J. (2005).When static media promote active learning: Annotated illustrations versus narrated animations in multimedia instruction. Journal of Experimental Psychology: Applied, 11(4), 256-265.

[50] Mayer, R. E., Heiser, J., \&Lonn, S. (2001). Cognitive constrains on multimedia learning: When presenting more material results in less understanding. Journal of Educational Psychology, 93(1), 187-198.

[51] Mayer, M. E., Mathias, A., Mathias, A., \&Wetzell, K. (2002).Fostering understanding of multimedia messages through pretraining: Evidence for two-stage theory of mental model construction.Journal of Experimental Psychology.Applied, 8(3), 147-154. 
[52] Mayer, R. E., \& Moreno, R. (1998). A split-attention effect in multimedia learning: Evidence for dual processing systems in working memory. Journal of Educational Psychology, 90, 312-320.

[53] Mayer, R. E., \& Moreno, R. (2002).Animation as an aid to multimedia learning.Educational Psychology Review, 14(1), 87-99.

[54] Mayer, R. E., \& Moreno, R. (2003).Nine ways to reduce cognitive load in multimedia learning.educational Psychologist, 38(1), 43-52.

[55] Miller, G. A. (1956). The magical number seven, plus or minus two; Some limits on our capacity for processing information. The Psychological Review. 63, 81-97.

[56] Moore, J.L., Lin, X., Schwartz, D.L., Petrosino, A., Hickey, D.T., Campbell, O., \&Hmelo, and The Cognition and Technology Group at Vanderbilt. (1994). The relationship between situated cognition and anchored instruction. Educational Technology, 34(8), 28-32.

[57] Moreno, R. (2007). Optimising learning from animations by minimizing cognitive load: Cognitive and affective consequences of signaling and segmentation methods. Applied Cognitive Psychology, 21(6), 765-781.

[58] Morrison, J.B., Tversky, B. \&Betrancourt, M. (2000). Animation: Does it Facilitate Learning?, AAAI Technical Report SS-00-04, Retrieved September 2014, from http://www.aaai.org/Papers/Symposia/Spring/2000/SS-00-04/SS00-04-009.pff.

[59] Najjar, L. J. (1998). Principles of educational multimedia user interface design. Hum Factors. 41, (2), 311-323.

[60] Nakhleh, M. B. (1992). Why some students don't learn chemistry: Chemical misconceptions. Journal of Chemical Education, 69 (3), 191-196.

[61] Paas, F. (1992). Training strategies for attaining transfer of problem-solving skill in statistics: A cognitive-load approach. Journal of Educational Psychology, 84(4), 429-434.

[62] Paas, F., Tuovinen, J. E., Tabbers, H. K., \& Van Gerven, P. W. M. (2003). Cognitive load measurement as a means to advance cognitive load theory.Educational Psychologist, 38(1), 63-71.

[63] Paas, F., Van Gerven, P. W. M., \&Wouters, P. (2007). Instructional efficiency of animation: Effects of interactivity through mental reconstruction of static key frames. Applied Cognitive Psychology, 21(6), 783-793.

[64] Park, O. (1998). Visual displays and contextual presentations in computer-based instruction.Educational Technology Research and Development, 46(3).37-50.

[65] Pavio, A. (1986). Mental representation: a dual-coding approach. New York: Oxford University Press.

[66] Phan, H. P. (2011). A cognitive multimedia environment and its importance: A conceptual model for effective e-learning and development. International Journal on E-Learning, 10(2), 199-221.

[67] Reiber, L.P. (1990). Using computer animated graphics inn science instruction with children. Journal of Educational Psychology, 82(1), 135-140.

[68] Reiber, L.P. (1991). Animation, incidental learning, and continuing motivation.Journal of Educational Psychology, 83(3), 318-328.

[69] Reiber, L.P., Boyce, M.J., \& Assad, C. (1990).The effects of computer animation on adult learning and retrieval tasks.Journal of Computer-Based Instruction, 17(2), 245-252.

[70] Reimann, P. (2003). Multimedia learning: Beyond modality. Learning and Instruction, 13(2), 245252.

[71] Ruiz, J.G., Cook, D.A., \& Levinson, A.J. (2009). Computer animations in medical education: a critical literature review. Medical Education, 43(9), 838-846.

[72] Rieber, L.P. (1990). Animation in computer-based instruction.Educ. Technol. Res. Dev. 39(1), 77-86.

[73] Sazbo, M., \&Poohkay, B. (1995).Effects of learning and visuals on learning high school mathematics.Proceedings of Annual Meeting of the Association for Educational Communications and Technology, Anaheim, CA.

[74] Sazbo, M., \&Poohkay, B. (1996).An experimental study of animation, mathematics achievement, and attitude toward computer-assisted instruction.Journal of Research on Computing in Education, 28(3), 390-402.

[75] Schnotz, W., \&Bannert, M. (2003). Construction and interference in learning from multiple representation. Learning and Instruction, 13(2), 141-156.

[76] Schnotz, W., \&Kürschner, C. (2008). External and internal representations in the acquisition and the use of knowledge: visualization effects on mental model construction. Ins. Sci.1(36), 175-190. 
[77] Schnotz, W., \&Rasch, T. (2005). Enabling, facilitating and inhabiting effects of animations in multimedia learning: why reduction of cognitive load can have negative results on learning. Educational.Technology.Research. Dev. 53(3), 47-58.

[78] Simonson, M., Smaldino, S., Albright, M. \&Zvacek, S. (2003). Teaching and learning at a distance: Foundations of distance education. Upper Saddle River, NJ: Merrill Prentice Hall.

[79] Spanjers, I. A. E., van Gog, T., \& van Merriënboer, J.J.G. (2010). A theoretical analysis of how segmentation of dynamic visualizations optimizes students' learning. Educational Psychology Review, 22(4), 411-423. (4), 411-423.

[80] Szabo, M., \&Poohkay, B. (1996).An experimental study of animation, mathematics achievement, and attitude towards computer-assisted instruction.Journal of Research on Computing in Education, 28(3), 390-402.

[81] Tannenbaum, R. S. (2000). Multimedia developers can learn from history of human communication. $\begin{array}{llll}\text { Ubiquity, } & \text { 1(34).Retrieved } & \text { November } & 2014,\end{array}$ http://www.acm.org/ubiquity/views/r_tannenbaum_3.html

[82] Trevisan, M.S., Oki, A.C. and Senger, P.L. (2008, December 24)"An Exploratory Study of the Effects of the Time Compressed Animated Delivery Multimedia Technology on Student”, Journal of Science Education and Technology, Vol. 19, No. 3, pp. 293-302.

[83] Tversky, B.,\& Morrison, J.B. (2001). Animation: Can It Facilitate?. Journal of Human-Computer Studies, 57(4), 247-262.

[84] Tversky, B.,\& Morrison, J.B. \&Betrancourt, M. (2002). Animation: Can it facilitate? International Journal of Human Computer Studies, 57(4), 247-262.

[85] Weiss, D. S. (1983). The effects of text segmentation on children's reading comprehension. Discourse Processes, 6(1), 77-89.

[86] Williams, P. J. (2000). Design: The only methodology of technology? Journal of Technology Education, 11(2), 48-60.

[87] Williamson, V.M., \& Abraham, M.R. (1995).The effect of computer animation on particulate mental models of collage chemistry student.Journal of Research in Science Teaching, 32(5), 521-534.

[88] Wouters, P., Paas, F., \& van Merriënboer, J.J. G. (2008). How to optimize learning from animated models: A review of guidelines based on cognitive load. Review of Educational Research,78(3), 645675.

[89] Wu, H. K., \& Shah, P. (2004).Exploring visuospatial thinking in chemistry learning.Science Education, 88 (3), 465-492.

[90] Yang, E. M., Andre, T., \&Greenbowe, T. Y. (2003).Spatial ability and the impact of visualization/animation on learning electrochemistry.International Journal of Science Education, 25(3), 329-349. 